\title{
Rectal sensorimotor characteristics in female patients with idiopathic constipation with or without paradoxical sphincter contraction
}

\author{
C. E. J. SLOOTS \& R. J. F. FELT-BERSMA
}

Department Of Gastroenterology, 'Vrije Universiteit' Medical Centre, Amsterdam, The Netherlands and Department of Gastroenterology and Hepatology, Erasmus Medical Centre, Rotterdam, The Netherlands

\begin{abstract}
Patients with chronic constipation fulfilling the Thompson criteria can show paradoxical sphincter contraction. Aim of this study was to evaluate rectal sensorimotor characteristics in patients with constipation with or without paradoxical sphincter contraction. Thirty female patients with chronic constipation and 22 female controls were investigated with anal manometry and rectal barostat. Paradoxical sphincter contraction was shown with manometry as a paradoxical increase of anal pressure during straining. Visceral sensitivity and compliance were tested by intermittent and continuous pressure-controlled distension. Patients were classified according to their sensations and compliance into normal, hypersensitive, reduced compliant, insensitive or excessive compliant rectum. Postprandial rectal response (PRR) and phasic volume events (PVEs) were registered for $1 \mathrm{~h}$ after a 600-kCal meal. Paradoxical sphincter contraction was found in $13(43 \%)$ patients. In these patients, rectal sensitivity scores were higher $(P=0.045)$ than in patients without paradoxical contractions, but rectal compliance was not different. In $90 \%$ of patients an abnormal rectal sensitivity or compliance was found: excessively compliant in $35 \%$, reduced compliant in 10\%, hypersensitive in $27 \%$ and hyposensitive in $17 \%$. Both patients with constipation
\end{abstract}

Address for correspondence

R. J. F. Felt-Bersma, M.D., PhD, Gastroenterologist, Department of Gastroenterology and Hepatology, Erasmus Medical Centre, P.O. Box 2040, 3000 CA Rotterdam, The Netherlands. Tel.: +31 10463 5946; fax: +31 10463 4682;

e-mail: rjf.felt@vumc.nl

Received: 9 December 2002

Accepted for publication: 11 December 2002
$(11 \% ; \quad P=0.042)$ and controls $(25 \% ; \quad P=0.002)$ exhibited the presence of a postprandial rectal response. This response was not significantly different between idiopathic constipation, paradoxical sphincter contraction and controls. Patients with rectal hypersensitivity had lower response than other patients $(P=0.04)$. Patients with constipation had fewer basal PVEs compared controls $(P=0.03)$. Postprandial $P V E$ s increased in both patients $(P=0.014)$ and controls $(P<0.001)$. Postprandial rectal response and PVE were not different in patients with or without paradoxical sphincter contraction. A total of $90 \%$ of female patients with idiopathic constipation show an abnormality in rectal sensation or compliance. The postprandial rectal response was comparable between patients with constipation and controls, however, PVEs were diminished. Patients with paradoxical sphincter contraction had higher rectal sensitivity but an unaltered compliance and postprandial rectal response. Future trials should investigate whether the classification of rectal abnormalities in patients with constipation has clinical importance.

Keywords barostat, constipation, paradoxical sphincter contraction, rectal motility, visceral sensitivity.

\section{INTRODUCTION}

Idiopathic constipation is characterized by infrequent bowel movements, hard stools, increased straining during defaecation and the feeling of incomplete evacuation. Subtypes of idiopathic constipation have been proposed to explain symptom complexes and findings during anorectal and colonic motility tests. Patients with chronic constipation have been categorized in three groups: slow transit, paradoxical sphincter contraction (PSC) and constipation-predominant irritable bowel syndrome (C-IBS). ${ }^{1}$ Idiopathic slow-transit 
constipation describes a symptom complex with symptoms of decreased bowel frequency poorly responsive to fibre and laxatives and a delayed transit time without a megacolon. ${ }^{2}$ The term slow-transit constipation generally refers to the patients with delayed colonic transit time. ${ }^{1}$ Besides delayed colonic transit, decreased colonic motor activity after a meal, fewer high-amplitude propagated contractions (HAPC), uncoordinated phasic rectal activity or irresponsiveness to a meal or a stimulant such as bisacodyl were found.$^{3-6}$ Possibly, slow-transit constipation represents a more generalized gastrointestinal dysmotility disorder. $^{7}$

Paradoxical sphincter contraction (anismus) is defined as an inappropriate contraction of the pelvic floor during straining, rather than relaxation. ${ }^{8}$ Anal manometry, electromyography (EMG) or defaecography can detect the paradoxical contraction of the anal sphincter. $^{9-12}$ Both slow or normal transit can be found in these patients. ${ }^{12,13}$

In C-IBS, bloating and pain are more prominent than decreased bowel frequency represented by an altered perception for rectal distension (visceral hypersensitivity). ${ }^{14,15}$ These patients with lower tolerance for balloon distension have high anxiety and depression scores. ${ }^{16}$ Possibly, IBS patient have different processing of bowel perception in the brain, as using the positron emission tomography (PET)-scan during rectal distension perception of rectal painful distension was associated with activation of different areas in the brain. ${ }^{17}$

However, a mixture of characteristics occurs in constipated patients. ${ }^{18}$ Where slow transit and IBS symptoms correlate with the physiological tests, measurements of paradoxical sphincter contraction show no correlation with pelvic-floor dysfunction symptoms. Patients with paradoxical sphincter contraction can show delayed colonic transit, even when the distal obstruction was removed. Patients with IBS can also have paradoxical sphincter contraction. ${ }^{20-22}$ Besides patients with paradoxical sphincter contraction, patients with features of slow-transit constipation respond to biofeedback training and the absence of paradoxical sphincter contraction does not preclude benefit. ${ }^{13,19}$ These findings make it rather confusing to propose a specific therapy, and leads to the hypothesis that besides paradoxical sphincter contraction, other abnormal rectal sensorimotor features are present and contribute to the clinical presentation. The aim of this study was to evaluate rectal sensitivity, compliance and postprandial rectal response in patients with chronic constipation with or without paradoxical sphincter contraction.

\section{PATIENTS AND METHODS}

\section{Subjects}

Thirty female patients (median age 35 years; range 20-77 years) were included. All patients presented complaints of more than two of the following criteria for at least 6 months:

- less than two bowel movements per week

- lumpy and/or hard stools for more than $25 \%$ of the time

- sense of incomplete evacuation for more than $25 \%$ of the time

- straining at defaecation for more than $25 \%$ of the time. ${ }^{23}$

All patients had less than two bowel movements per week and at least one of the other criteria. All patients were treated with laxatives and/or enemas, however, they felt their treatment was insufficient. Digital manoeuvres were not reported. None of the patients presented alternating constipation and diarrhoea. Abdominal pain or distension or bloating was not their main concern. None of the patients had a history of abdominal surgery. Colonoscopy was performed to exclude organic disease. According to the patients' clinicians, they were classified as idiopathic constipation and sent to our laboratory for evaluation. We performed rectal examination and anal manometry. Defaecography was performed to exclude anatomical disorder when suspected, no significant rectal intussusception or enterocele were found. Colonic transit time measurement was performed to show slow transit, however in half of the included patients, these tests were not reliable as patients could not stop using laxatives.

Twenty-two healthy female controls (median age 30 years and range 20-59 years) were recruited by advertising. The controls had normal bowel habits without history of constipation or abdominal surgery and did not use medication. Females who participated in the study were not pregnant. Three groups were identified for comparison:

1 Idiopathic constipation: patients with chronic constipation without signs of paradoxical sphincter contraction on anal manometry;

2 Paradoxical sphincter contraction: patients with chronic constipation with signs of paradoxical sphincter contraction on manometry;

3 Healthy controls.

The protocol was approved by the local Ethics Committee and written informed consent was given by each subject. 


\section{Anal manometry}

Anal manometry was performed according to our methods as described previously. ${ }^{24}$ To determine relaxation of the pelvic floor, the patients were asked to strain with the pressure catheter in situ. ${ }^{8,9,13}$ Paradoxical sphincter contraction was defined as maximal basal pressure more than $60 \mathrm{mmHg}$ and paradoxical increase of anal pressure during straining more than $10 \mathrm{mmHg}$.

\section{Barostat}

Subjects presented to the unit after an overnight fast. The subjects had bowel preparation with an enema. The subjects were positioned on their back with the head lowered to $15^{\circ}$. The barostat-balloon was inserted in the rectum, just behind the anal verge. The barostat system consisted of the following: a flaccid polyethylene bag (maximal capacity $600 \mathrm{~mL}$ ) was fixated on a double-lumen catheter tube (diameter $5 \mathrm{~mm}$ ). After inflation, the balloon had a cylindrical shape with a length of $10 \mathrm{~cm}$. The catheter was connected with an electronic barostat device (Synectics visceral stimulator; Synectics medical, Stockholm, Sweden) with two connections, an inflation port and a pressure port for intrabag pressure measurement. Maximal airflow was $38 \mathrm{~mL} \mathrm{~s}^{-1}$. With a feedback mechanism, the barostat device can regulate pressure or volume in the bag. Procedures were stopped if the safety value of the maximal volume of $600 \mathrm{~mL}$ or the pressure of $50 \mathrm{mmHg}$ was exceeded or if the patient was unable to hold the distension. ${ }^{25}$

\section{Procedures}

The following procedures were performed in a standard order:

1. Conditioning distension Rectal volume controlled distension was performed at a rate of $30 \mathrm{~mL} \mathrm{~min}^{-1}$ until maximal-tolerated distension. This 'conditioning' distension was performed in order to reduce and stabilize basal tone, to familiarize subjects with the procedure and enhance reproducibility. ${ }^{26}$

2. Intermittent pressure distension (IPD) Rapid rectal distension was performed in a semi-random staircase manner at the pressures $8,12,20,16,32,24,36$ and $28 \mathrm{mmHg}$. Pressure distension was continued $1 \mathrm{~min}$ followed by 1-min rest. Volume and visceral sensitivity was registered after $30 \mathrm{sec}$ of adaptation. Visceral sensitivity (VSS) was scored from 0 to $5(0=$ no feeling,
$1=$ light sensation, $2=$ clear feeling or beginning urge, $3=$ normal urge (as they would go to the toilet), $4=$ strong urge (as they would haste to the toilet) and $5=$ maximal tolerated or pain). When unbearable pain was reported and the procedure had to be interrupted, only the next (lower) pressure was offered after which the following distensions were omitted.

3. Continuous pressure distension (CPD) Rectal distension was accomplished by pressure-controlled ramp inflation until $36 \mathrm{mmHg}$ in $10 \mathrm{~min}$. Volume was registered continuously and sensitivity was registered at pressure steps of $4 \mathrm{mmHg}$. Then, deflation was performed in $10 \mathrm{~min}$ to register hysteresis. Hysteresis was being defined as the relative difference between the area under the pressure volume curve (AUC) in the ascending and descending part [(AUC $\left.\mathrm{desc}-\mathrm{AUC}_{\mathrm{asc}}\right) /$ $\mathrm{AUC}_{\text {desc }} .^{27}$ Minimal distension pressure (MDP; i.e. pressure which keeps the bag from being completely collapsed) was registered. Dynamic compliance was calculated as volume increase during pressure disten$\operatorname{sion}(\Delta \mathrm{V} / \Delta \mathrm{P})$.

4. Postprandial rectal response An isobaric barostat procedure was conducted at $2 \mathrm{mmHg}$ above MDP. After 30-60 min of basal registration when a stable volume was reached, a liquid meal was given consisting of $400 \mathrm{ml}$ of Ensure plus ${ }^{\circledR}(600 \mathrm{kCal}, 17 \%$ protein, $53 \%$ carbohydrates, $30 \%$ fat). After the meal, volume and intraballoon pressure was recorded for $1 \mathrm{~h}$. A meal response was defined as a more than $10 \%$ decrease in postprandial volume after $1 \mathrm{~h}$. Phasic volume events (PVEs) were defined as $10 \%$ decrease in volume with duration of $15-60 \mathrm{s.}^{28,29}$

\section{Data and statistical analysis}

Results are presented as means with standard error of the mean (SEM) or medians when appropriate. Volume pressure curves and VSS-pressure curves were compared in the groups using the ANOVA method for repeated measurements.

Rectal sensitivity and rectal compliance were classified using the $95 \%$ confidence interval of the values of the controls. Rectal sensitivity was defined as hypersensitivity (VSS above 5-95\% range of the controls: unable to hold distension until $36 \mathrm{mmHg}$ in both the intermittent and the continuous distension), normosensitivity (VSS within the 5-95\% range) or hyposensitivity (VSS below the 5-95\% range). Rectal compliance was categorised in low, normal and high compliant after comparing the curve to the $95 \%$ confidence interval of the controls. Rectal sensitivity 
and compliance were combined following the classification according to Prior et al. ${ }^{30}$

1 Normal rectum (normal sensitivity and compliance)

2 Hypersensitive rectum (hypersensitivity and low or normal compliance)

3 Reduced compliant rectum (normosensitive and low compliance)

4 Insensitive rectum (hyposensitivity and normal or low compliance)

5 Excessive compliant rectum (normosensitivity or hyposensitivity and high compliance).

Rectal volumes measured during the postprandial rectal response were analysed as mean volumes over 5 -min periods. Results are presented as mean volume with SEM or as percentages, relative to baseline volume. Pre- and post-prandial data were compared using the ANOva method for repeated measurements. Phasic volume events were calculated by Polygram 2.04 software (Synectics medical, Stockholm, Sweden) and reviewed by the investigator. Basal and postprandial PVEs were compared using the Student's $t$-test.

\section{RESULTS}

Thirteen of the 30 patients (43\%) showed paradoxical contraction of the anal sphincter during straining and 17 patients had a normal pattern of sphincter function in association with constipation (idiopathic constipation).

\section{Visceral sensitivity}

Comparison of results between paradoxical sphincter contraction, idiopathic constipation and controls revealed that paradoxical sphincter contraction had higher $(P=0.045)$ rectal sensitivity than idiopathic constipation but not than controls (Fig. 1).

The patients were classified according to the 5-95\% range of the controls in three sensitivity groups. Eight patients $(25 \%)$ were found to be hypersensitive, sixteen $(55 \%)$ were normosensitive and six patients $(20 \%)$ had a hyposensitive rectum. Paradoxical sphincter contraction was present in five of eight patients with hypersensitive, seven of 16 normosensitive and one of six hyposensitive rectum $(P=0.23)$.

Intermittent or continuous pressure distension did not reveal different sensitivity scores (Fig. 2).

\section{Compliance}

Volume pressure curves were neither different between the continuous and the intermittent procedure in paradoxical sphincter contraction, idiopathic constipation

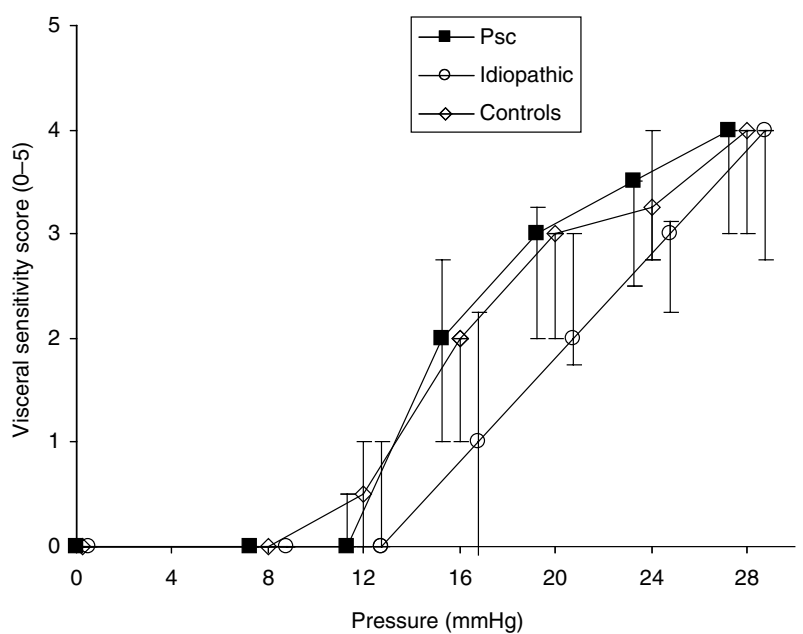

Figure 1 Line chart showing visceral sensitivity score during intermittent pressure distension in patients with paradoxical sphincter contraction (psc), with idiopathic constipation and controls. Medians and 25-75th range. Paradoxical sphincter contraction vs Idiopathic $(P=0.045)$.

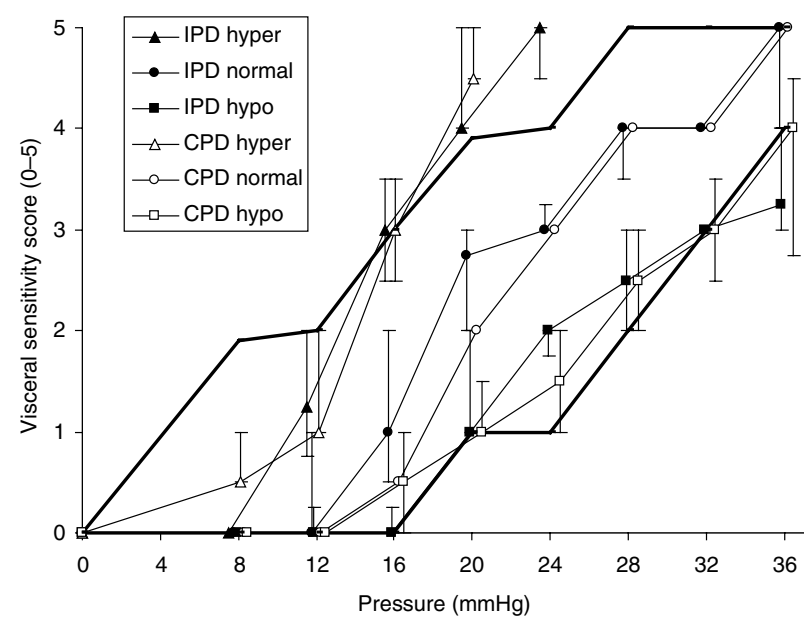

Figure 2 Line chart showing visceral sensitivity during intermittent pressure distension (IPD, closed symbols) and during continuous pressure distension (CPD, open symbols) in hypersensitive, normosensitive and hyposensitive patients compared with the 5-95\% range of the controls (fat lines). Medians and 25-75th range. No difference was found between IPD and CPD in visceral sensitivity.

controls nor different between hypersensitive, normo and hyposensitive groups and the controls. Also, static compliance was not different between the hyper-, normo- and hypo-sensitivity patients. The patients could be classified according to the $95 \%$ confidence interval of the controls in three compliance groups (Fig. 3). A low compliant rectum was found in nine patients $(30 \%)$, normal in $10(33 \%)$ and high in $11(37 \%)$. 


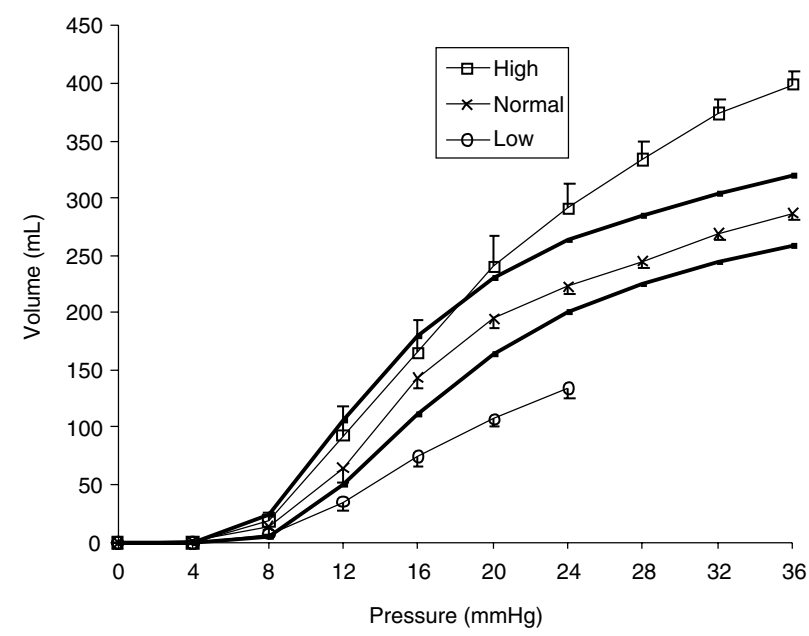

Figure 3 Line chart showing compliance curves during continuous pressure distension. The patients are divided in low, normal and high compliant and compared with the $95 \%$ confidence interval of the controls (fat lines). Mean and SEM.

Figure 4 shows the combination of the abnormalities of compliance and sensitivity. A rectal abnormality was found in $90 \%$ of the patients.

Hysteresis could not be assessed in patients with a hypersensitive rectum, as the pressure of $36 \mathrm{mmHg}$ could not be reached. Hysteresis did not differ between patients with normosensitive $(0.27 \pm 0.03)$ and hyposensitive patients $(0.30 \pm 0.03)$ with constipation and controls $(0.28 \pm 0.02)(P=\mathrm{NS})$.

\section{Postprandial rectal response}

Basal pressure was not significantly different between idiopathic constipation $(12.4 \pm 0.6 \mathrm{mmHg})$, paradoxical sphincter contraction $(12.3 \pm 0.6 \mathrm{mmHg})$ and controls $(11.8 \pm 0.3 \mathrm{mmHg})$. Rectal volume after the adaptation period was not significantly different

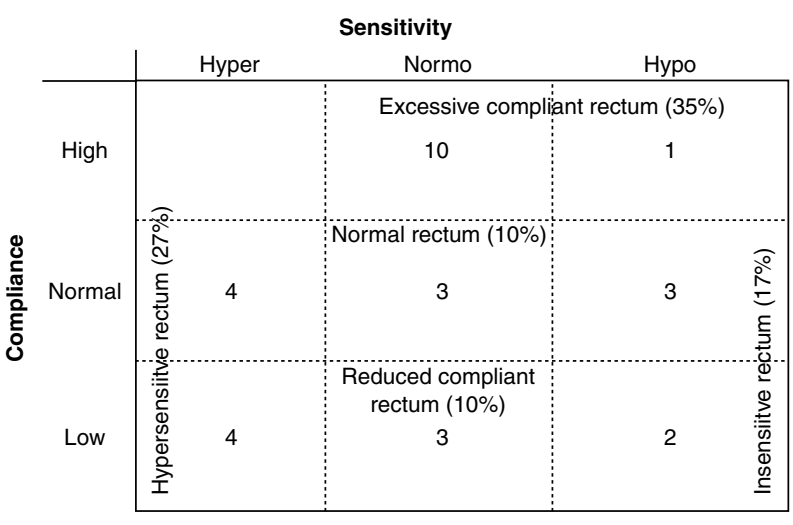

Figure 4 Constipated patients characterized according Prior et al. ${ }^{30}$

between idiopathic constipation $(162 \pm 11 \mathrm{~mL})$, paradoxical sphincter contraction $(157 \pm 23 \mathrm{~mL})$ and controls $(138 \pm 10 \mathrm{~mL} ; P=0.15)$. Postprandial volume decreased significantly to $144 \pm 13 \mathrm{~mL}$ in patients $(11 \% ; P=0.042)$ and to $103 \pm 12 \mathrm{~mL}$ in controls $(25 \% ; P=0.002)$. The difference in postprandial volume between patients $(11 \%)$ and the controls $(25 \%)$ was not significant. There was also no significant difference in postprandial volume between paradoxical sphincter contraction, idiopathic constipation and controls. Hypersensitive patients (increase of $4 \%$ ) had a significant $(P=0.04)$ lower response than other patients. Compliance did not influence the postprandial rectal response (Fig. 5).

Patients $\left(0.4 \pm 0.3 \mathrm{~h}^{-1}\right)$ had significantly $(P=0.03)$ less PVEs preprandially than controls $\left(3.0 \pm 1.1 \mathrm{~h}^{-1}\right)$. Postprandial PVEs increased in both patients $(P=0.014)$ and controls $(P<0.001)$. Postprandially, patients had less PVEs than controls $(2.3 \pm 0.5$ vs. $\left.8.5 \pm 1.7 \mathrm{~h}^{-1} ; P=0.002\right)$. The pre- and post-prandial amount of PVEs did not differ significantly between
Figure 5 Line chart showing postprandial rectal response in patients with a normal rectum, hypersensitive rectum, insensitive rectum, excessive compliant rectum and a reduced compliant rectum. Patients with a hypersensitive rectum had a significant lower response compared with the other patients $(P=0.04)$.

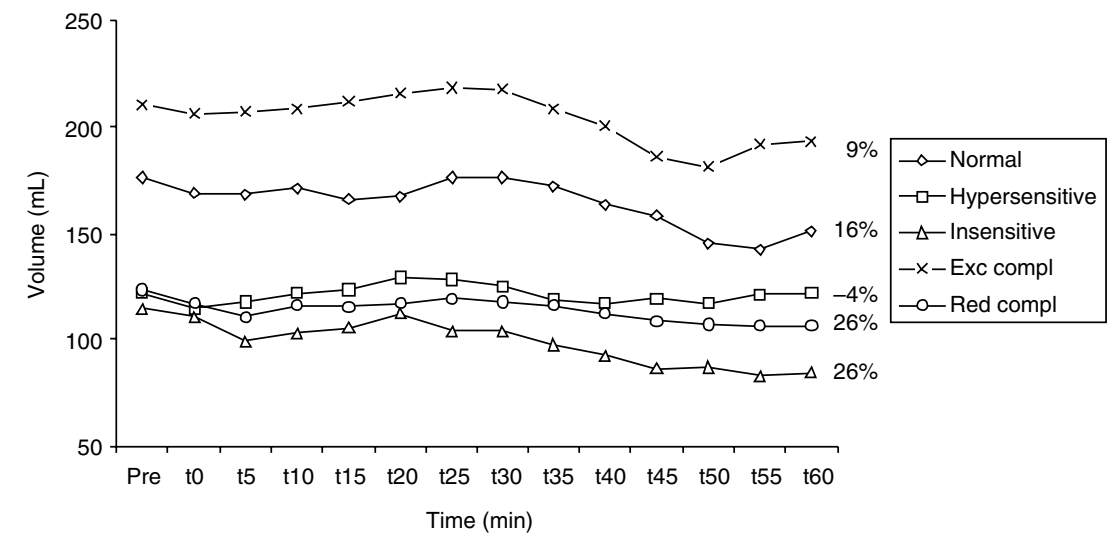


idiopathic constipation patients and paradoxical sphincter contraction patients.

\section{DISCUSSION}

Chronic constipation harbors subgroups of patients with chronic idiopathic constipation, pelvic floor dysfunction and constipation predominant bowel syndrome. In most reports, constipated patients have diminished sensitivity compared with controls. ${ }^{31,32}$ We found abnormal rectal sensitivity and compliance in $90 \%$ of the patients after classification of the patients into five separate groups following Prior et al. ${ }^{30}$ An excessive compliant rectum was found in $35 \%$ accounting for the largest group. Hypersensitivity occurred in $26 \%$ of the constipated patients. Mertz et al. stated that hypersensitivity is considered a biological marker of irritable bowel syndrome. The C-IBS patients could present with a particular hypersensitive and increased rectal compliance. ${ }^{15}$ On these criteria, patients with rectal hypersensitivity in our group of patients could also have been classified as C-IBS. Paradoxical sphincter contraction was shown in approximately $60 \%$ of the hypersensitive patients, which is in agreement with the study of Mertz et al. ${ }^{20}$ Furthermore, we found that patients with paradoxical sphincter contraction compared with idiopathic constipation patients had higher rectal sensitivity without a different compliance. In contrast, Rao et al. found that patients with obstructed defaecation compared with non-obstructive defaecation had increased volume threshold for first sensation, which decreased significantly after biofeedback. ${ }^{12,33}$ Patient selection criteria are the cause of the difference in findings between the studies.

Paradoxical sphincter contraction (anismus) is a disturbed relaxation of the striated pelvic floor and anal musculature leading to a functional obstruction of defaecation at the pelvic outlet. ${ }^{8}$ Critical remarks towards paradoxical sphincter contraction should be made based on the presence in controls and patients with faecal incontinence and inconsistency of the criteria for diagnosis. ${ }^{10,34}$ In our view, paradoxical sphincter contraction consist of a high anal rest tone and a paradoxical increase during straining together with a heightened visceral sensitivity.

In our study, we found that the postprandial rectal tone response was not different between constipated patients and controls. In addition, we found that hypersensitive constipated patients had the lowest response. We found that constipated patients had fewer PVEs than controls, both pre- and post-prandial. Conflicting studies were reported on the postprandial rectal tone response in constipated patients. Some investigators found a blunted response to a meal in patients with chronic constipation and in patients with slowtransit or outlet obstruction. ${ }^{35-37}$ One study could not find differences in postprandial rectal tone between patients with slow transit, constipation predominant IBS and controls. ${ }^{38}$ The postprandial rectal response is diminished in patients with constipation, however, the complexity of the response and the heterogeneous population makes it difficult to draw firm conclusions.

In conclusion, $90 \%$ of the female patients with idiopathic constipation show an abnormality in rectal sensation or compliance, which can be classified as excessive compliant $(35 \%)$, hypersensitive $(27 \%)$, insensitive $(17 \%)$, reduced compliant $(10 \%)$ or normal $(10 \%)$. The postprandial rectal response was comparable between patients with constipation and controls, however, PVEs were diminished. Patients with paradoxical sphincter contraction had higher rectal sensitivity but unaltered compliance and postprandial rectal response. Whether these tests and subsequent classifications are useful, should appear from future trials.

\section{REFERENCES}

1 Bharucha AE, Phillips SF. Disorders of the anorectum: slow transit constipation. Gastroenterol Clin NA 2001; 30: 77-95.

2 Preston DM, Lennard-Jones JE. Severe chronic constipation of young women: 'idiopathic slow transit constipation'. Gut 1986; 27: 41-8.

3 Rao SSC, Sadeghi P, Beaty J, Kavelock R, Ackerson K. Ambulatory 24-h colonic manometry in healthy humans. Am I Physiol 2001; 280: G629-39.

4 Bassotti G, Chiarioni G, Vantini I et al. Anorectal manometric abnormalities and colonic propulsive impairment in patients with severe chronic idiopathic constipation. Dig Dis Sci 1994; 39: 1558-64.

5 Rao SSC, Sadeghi P, Batterson K, Beaty J. Altered periodic rectal motor activity: a mechanism for slow transit constipation. Neurogastroenterol Motil 2001; 13: 591-8.

6 Preston DM, Lennard-Jones JE. Pelvic motility and response to intraluminal bisacodyl in slow transit constipation. Dig Dis Sci 1985; 30: 289-94.

7 Altomare DF, Portincasa P, Rinaldi M et al. Slow-transit constipation: solitary symptom of a systemic gastrointestinal disease. Dis Colon Rectum 1999; 42: 231-40.

8 Preston DM, Lennard-Jones JE. Anismus in chronic constipation. Dig Dis Sci 1985; 30: 413-8.

9 Rao SS, Hatfield R, Soffer E, Rao S, Beaty J, Conklin JL. Manometric tests of anorectal function in healthy adults. Am I Gastroenterol 1999; 94: 773-83.

10 Rao SSC, Patel RS. How useful are manometric tests of anorectal function in the management of defecation disorders? Am J Gastroenterol 1997; 92: 469-75.

11 Whitehead WE, Wald A, Diamant NE, Enck P, Pemberton $\mathrm{JH}, \mathrm{Rao}$ SS. Functional disorders of the anus and rectum. Gut 1999; 45 (Suppl 2): II55-9. 
12 Rao SSC, Welcher K, Leistikow J. Obstructive defecation: a failure of rectoanal coordination. Am J Gastroenterol 1998; 93: $1042-50$.

13 Koutsomanis D, Lennard-Jones JE, Kamm MA. Prospective study of biofeedback treatment for patients with slow and normal transit constipation. Eur I Gastroenterol Hepatol 1994; 6: 141-7.

14 Thompson WG, Longstreth GF, Drossman DA, Heaton KW, Irvine EJ, Müller-Lissner SA. Functional bowel disorders and functional abdominal pain. Gut 1999; 45(Suppl 2): II43-7.

15 Mertz H, Naliboff B, Munakata J, Niazi N, Mayer EA. Altered rectal perception is a biological marker of patients with irritable bowel syndrome. Gastroenterology 1995; 109: 40-52.

16 Whitehead WE, Crowell MD, Davidoff AL, Palsson OS, Schuster MM. Pain from rectal distension in women with irritable bowel syndrome. Dig Dis Sci 1997; 42: 796-804.

17 Silverman DHS, Munakata J, Ennes H, Mandelkern MA, Hoh CK, Mayer EA. Regional cerebral activity in normal and pathological perception of visceral pain. Gastroenterology 1997; 112: 64-72.

18 Glia A, Lindberg G, Nilsson LH, Mihocsa L, Åkerlund JE. Constipation assessed on the basis of colorectal physiology. Scand J Gastroenterol 1998; 33: 1272-9.

19 Chiotakakou-Faliakou E, Kamm MA, Roy AJ, Storrie JB, Turner IC. Biofeedback provides long term benefit for patients with intractable, slow and normal transit constipation. Gut 1998; 42: 517-21.

20 Mertz H, Naliboff B, Mayer EA. Physiology of refractory chronic constipation. Am J Gastroenterol 1999; 94: 609-15.

21 Sloots CEJ, Felt-Bersma RJF. Effect of bowel cleansing on colonic transit in constipation due to slow transit or evacuation disorder. Neurogastroenterol Motil 2002; 14: 55-61.

22 Mertz H, Naliboff B, Mayer EA. Symptoms and physiology in severe chronic constipation. Am J Gastroenterol 1999; 94: $131-8$.

23 Thompson WG, Heaton KW. Functional bowel disorders in apparently healthy people. Gastroenterology 1980; 79: 283-8.

24 Poen AC, de Brauw M, Felt-Bersma RJ, de Jong D, Cuesta MA. Laparoscopic rectopexy for complete rectal prolapse. Clinical outcome and anorectal function tests. Surg Endosc 1996; 10: 904-8.

25 Whitehead WE, Delvaux $M$ and the Working Team. Standardization of the barostat procedures for testing smooth muscle tone and sensory thresholds in the gastrointestinal tract. Dig Dis Sci 1997; 2: 223-41.
26 Hammer HF, Phillips SF, Camilleri M, Hanson RB. Rectal tone, distensibility and perception: reproducibility and response to different distensions. Am J Physiol 1998; 274: G584-90.

27 Bharucha AE, Hubmayr RD, Ferber IJ, Zinsmeister. Viscoelastic properties of the human colon. Am I Physiol 2001; 281: G459-66.

28 Bell AM, Pemberton JH, Hanson RB, Zinsmeister AR. Variations in muscle tone of the human rectum: recordings with an electromechanical barostat. Am I Physiol 1991; 260: G17-25.

29 Von der Ohe MR, Hanson RB, Camilleri M. Comparison of simultaneous recording of human colonic contractions by manometry and a barostat. Neurogastroenterol Motil 1994; 6: 213-22.

30 Prior A, Maxton DG, Whorwell PJ. Anorectal manometry in irritable bowel syndrome: differences between diarrhoea and constipation predominant subjects. Gut 1990; 31: 458-62.

31 Shouler P, Keighley MRB. Changes in colorectal function in severe idiopathic chronic constipation. Gastroenterology 1986; 90: 414-20.

32 Gosselink MJ, Schouten WR. Rectal sensory perception in females with obstructed defecation. Dis Colon Rectum 2001; 44: 1337-44.

33 Rao SSC, Welcher KD, Pelsang RE. Effects of biofeedback therapy on anorectal function in obstructive defecation. Dig Dis Sci 1997; 42: 2197-205.

34 Voderholzer WA, Neuhaus DA, Klauser AG, Tzavella K, Müller-Lissner SA, Schindlbeck NE. Paradoxical sphincter contraction is rarely indicative of anismus. Gut 1997; 41: 258-62.

35 Grotz RL, Pemberton JH, Levin KE, Bell AM, Hanson RB. Rectal wall contractility in healthy subjects and in patients with chronic severe constipation. Ann Surg 1993; 218: 761-8.

36 O'Brien MD, Camilleri M, Van der Ohe MR et al. Motility and tone of the left colon in constipation: a role in clinical practice? Am I Gastroenterol 1996; 91: 2532-8.

37 Mollen RM, Salvioli B, Camilleri M et al. The effects of biofeedback on rectal sensation and distal colonic motility in patients with disorders of rectal evacuation: evidence of an inhibitory rectocolonic reflex in humans? Am J Gastroenterol 1999; 94: 751-6.

38 Penning C, Steens J, van der Schaar PJ et al. Motor and sensory function of the rectum in different subtypes of constipation. Scand I Gastroenterol 2001; 36: 32-8. 